\title{
Effect of Ultrasound-Assisted Extraction of Phenolic Compounds on the Characteristics of Walnut Shells
}

\author{
Hannah Han1, Shusheng Wang', Milan Rakita ${ }^{3}$, Yanting Wang ${ }^{4}$, Qingyou Han ${ }^{3}$, Qin $\mathrm{Xu}^{4}{ }^{*}$ \\ ${ }^{1}$ Henry Samueli School of Engineering and Applied Science, University of California, Los Angeles, CA, USA \\ ${ }^{2}$ School of Life Sciences, Jilin Agricultural University, Changchun, China \\ ${ }^{3}$ School of Engineering Technology, Purdue University, West Lafayette, IN, USA \\ ${ }^{4}$ School of Agriculture, Purdue University, West Lafayette, IN, USA \\ Email: *xuq@purdue.edu
}

How to cite this paper: Han, H., Wang, S.S., Rakita, M., Wang, Y.T., Han, Q.Y. and Xu, Q. (2018) Effect of Ultrasound-Assisted Extraction of Phenolic Compounds on the Characteristics of Walnut Shells. Food and Nutrition Sciences, 9, 1034-1045.

https://doi.org/10.4236/fns.2018.98076

Received: July 26, 2018

Accepted: August 20, 2018

Published: August 23, 2018

Copyright $\odot 2018$ by authors and Scientific Research Publishing Inc. This work is licensed under the Creative Commons Attribution International License (CC BY 4.0).

http://creativecommons.org/licenses/by/4.0/

\begin{abstract}
Walnuts are one of nature's more waste-heavy products. $67 \%$ of the nut is shell and husk, low value by-products that are rich in phenolic compounds. The phenolic compounds extracted from walnut shells are potentially good natural sources of antioxidants for the food and pharmaceutical industries. In this study, phenolic compounds were extracted using an ultrasonic bath, an ultrasonic probe and a standard shaking method. The extraction yield achieved with an ultrasonic probe was $51.2 \mathrm{mg} \mathrm{GAE} / \mathrm{g} \mathrm{DW}$, two times higher than both the shaking method and the ultrasonic bath method which were $20.6 \mathrm{mg} \mathrm{GAE} / \mathrm{g} \mathrm{DW}$ and $25.8 \mathrm{mg} \mathrm{GAE} / \mathrm{g} \mathrm{DW}$, respectively. Phenolic extraction was further improved by a size reduction of the walnut shells. The best extraction yield of $52.8 \mathrm{mg} \mathrm{GAE} / \mathrm{g}$ DW was attained when the particle size was between $45-100$ mesh. The ultrasonic probe treatment is the best method for extraction of phenolic compounds from walnut shells. Scanning electron microscopy (SEM) imaging indicated that the ultrasonic probe treatment could better rupture the hard structure of the cells, increasing the penetration of solvents and thus the extraction yield.
\end{abstract}

\section{Keywords}

Walnut Shell, Ultrasound-Assisted Extraction, Total Phenolic Content (TPC), Particle Size, SEM Analysis

\section{Introduction}

Walnuts (Juglans regia) are cultivated worldwide for their edible kernels which 
are enclosed in a hard shell [1]. The worldwide walnut production of the whole nut in 2014 was approximately 3.45 million tons, meaning that around 2.3 million tons of walnut shells are left behind since the shell comprises $67 \%$ of the total weight of a walnut [2]. The shell is composed of $22.2 \%$ (wt.) hemicellulose, $25.5 \%$ (wt.) cellulose and 52.3\% (wt.) lignin [3]. This structural composition allows for the shell to be hard, nontoxic, biodegradable and renewable [3]. Sclerenchyma cells are also present in the shell and support tissues that are no longer expanding [4]. The secondary walls of walnut shells form thick, rigid and hard layers with lignified cells [5].

As agricultural waste, walnut shells are burned in the winter to produce heat, but this usage method is energy inefficient and pollutes the air [2]. Walnut shells are rich in phenolic acids and related polyphenols that, as shown in other studies, bear numerous health-promoting effects [6]. As the need for natural antioxidants is dynamically increasing in the food industry, agricultural and food waste is becoming an ideal substance from which to extract phenolic compounds as natural antioxidants [7]. Currently, increased research efforts are focused on the recycling of inexpensive waste products from the food, forest and agricultural industries due to the environmental and economic benefits [8] [9].

Walnuts exhibit greater antioxidant capacity than any other nut [10] as the shell is mainly composed of lignin, a strong phenolic source. Natural antioxidants, like phenolic compounds, are gaining relevance for their positive effects on human health such as decreasing the risk of degenerative diseases by reducing oxidative stress and inhibiting macromolecular oxidation [1] [11]. Other health benefits include a wide range of physiological properties, such as anti-allergenic, anti-atherogenic, anti-inflammatory, antimicrobial, antioxidant, antithrombotic, cardioprotective and vasodilatory effects [8] [11]. Transparency Market Research has predicted that the global demand for polyphenolic compounds in 2018 will be expected to reach 873.7 million USD with a $6.1 \%$ of annual growth rate from 2012 to 2018 [12]. Phenolics are also used in the food industry as a food stabilizer and currently are considered more powerful and potent antioxidants than vitamin C, vitamin E and carotenoids [13] [14].

Novel extraction methods to obtain nutraceuticals from plants include shaking extraction, ultrasound-assisted extraction (UAE), microwave-assisted extraction [9], supercritical fluid extraction [15], ohmic heating [16] and pressurized liquid extraction [9]. Among these techniques, UAE is relatively efficient and cost effective [17] [18] [19] [20]. The mechanical action of ultrasound cracks suspended sample particles which increases the contact surface area between the solid and liquid phases, causing greater penetration of solvent into the sample matrix and resulting in quicker diffusion of the solute from the solid phase to the solvent [17] [18] [21]. The ultrasonic extraction of biological materials requires relatively high power and densities of over $30 \mathrm{~W} / \mathrm{cm}^{2}$ with frequencies between 20 and $500 \mathrm{kHz}$. The injection of high intensity ultrasonic vibrations into a liquid causes a number of non-linear physical phenomena such as cavitation and acoustic streaming that alters the reaction and diffusion kinetics and accelerates 
the extraction of chemical substances from the sample particles suspended in the liquid [22] [23].

The main method for ultrasound-assisted extraction of chemicals from agricultural waste involves the use of ultrasonic baths. Ultrasonic vibrations are applied through probes to the walls of the bath and then transmitted into the liquid. Acoustic energy is applied indirectly to the medium containing solid sample particles, leading to energy loss and reduced vibration intensity in the liquid. Alternatively, in an ultrasonic probe system, ultrasonic vibrations are directly applied to the extraction liquid, effectively transmitting ultrasonic energy to enhance cavitation and acoustic streaming [23] [24]. At higher ultrasonic energies, the extraction of organic compounds from plants is improved due to severe acoustic cavitation. The collapse of cavitation bubbles creates regions of high temperature and pressure as well as shock waves that provide greater penetration of the solvent into the cellular material and help mass transfer to and from interfaces for the disruption of cell walls and release of cellular materials [22] [23] [24] [25]. Still, little research has been found in literature on the effectiveness of using ultrasonic probes directly on liquid mediums for phenolic extraction from walnut shells. The objective of this study is to determine the effect of UAE on phenolic yields from walnut shells and to analyze the impact of different treatment methods on the structure of walnut shells.

\section{Materials and Methods}

\subsection{Chemicals}

All chemicals including ethanol, Folin-Ciocalteu reagent and gallic acid were obtained from Fisher Scientific.

\subsection{Materials}

Walnut shell chips (moisture content $7.41 \%$ ) were provided by Sierra Orchards in California. The walnut shell powder was screened through $45(0.354 \mathrm{~mm})$ and $100(0.150 \mathrm{~mm})$ mesh after being grinded by a spice grinder (Model No. WSG 30, Waring Products, USA). The samples were stored in the refrigerator for further use.

\subsection{Extraction of Phenolic Compounds}

\subsubsection{Shaking Method}

$1.5 \mathrm{~g}$ of ground walnut shell powder (dry weight) was suspended in $30 \mathrm{~mL}$ of $50 \%(\mathrm{v} / \mathrm{v})$ ethanol/water at $25^{\circ} \mathrm{C}$. For $15 \mathrm{~min}$ in the dark, the mixture was placed in an incubator shaker (Environmental Incubator Shaker, G24, New Brunswick Co., Inc., Edison, NJ, USA) at $150 \mathrm{rpm}$. After the treatment the sample was immediately centrifuged (Allegra ${ }^{\oplus}$ 6, Beckman Coulter, Inc., Indianapolis, IN, USA) at $3000 \mathrm{rpm}$ for $15 \mathrm{~min}$. The supernatant was collected for phenolic content analysis, and the precipitate was oven dried overnight at $45^{\circ} \mathrm{C}$ for SEM analysis. 


\subsubsection{Ultrasonic Bath Method}

$1.5 \mathrm{~g}$ of ground walnut shell powder (dry weight) was suspended in $30 \mathrm{~mL}$ of $50 \%(\mathrm{v} / \mathrm{v})$ ethanol/water at $25^{\circ} \mathrm{C}$. The mixture was placed in the dark for $15 \mathrm{mi}-$ nutes in an ultrasonic water bath (SharperTek ${ }^{\circledR}$, Pontiac, MI, USA) set at a frequency of $40 \mathrm{kHz}(500 \mathrm{~W})$. After the treatment, the sample was immediately centrifuged at $3000 \mathrm{rpm}$ for $15 \mathrm{~min}$. The supernatant was collected for phenolic content analysis, and the precipitate was oven dried overnight at $45^{\circ} \mathrm{C}$ for SEM analysis.

\subsubsection{Ultrasonic Probe Method}

$1.5 \mathrm{~g}$ of ground walnut shell powder (dry weight) was suspended in $30 \mathrm{~mL}$ of $50 \%(\mathrm{v} / \mathrm{v})$ ethanol/water at $25^{\circ} \mathrm{C}$. The mixture was agitated with an ultrasonic probe in the dark for $15 \mathrm{~min}$. The ultrasonic equipment consisted of an amplifier (Model VCF1500, Sonics \& Materials, Newtown, CT, USA), an air-cooled piezoelectric converter (Model CV-294, Sonics and Materials, Newton, CT, USA) and a probe of $19 \mathrm{~mm}$ immersed $1 \mathrm{~cm}$ deep into the mixture. The drive frequency was set at $22.95 \mathrm{kHz}$ with an output power of $1500 \mathrm{~W}$. After the treatment, the sample was immediately centrifuged at $3000 \mathrm{rpm}$ for $15 \mathrm{~min}$. The supernatant was collected for phenolic content analysis, and the precipitate was oven dried overnight at $45^{\circ} \mathrm{C}$ for SEM analysis.

\subsection{Quantification of Total Phenolic Compounds}

The total phenolic content was determined by the Folin-Ciocalteu method [26] with some modifications. $0.5 \mathrm{~mL}$ of the extracted solution was mixed with $2.5 \mathrm{~mL}$ of Folin-Ciocalteu reagent (10-fold diluted). After three minutes of mixing, an additional $2 \mathrm{~mL}$ of $7.5 \%$ sodium carbonate solution was added. The reaction was then heated at $45^{\circ} \mathrm{C}$ for $15 \mathrm{~min}$. The absorbance was read at $765 \mathrm{~nm}$ using a blank of water and reagents. The phenolic content was calculated as gallic acid equivalents from the calibration curve of gallic acid standard solutions (0.01 $1 \mathrm{mM}$ ) and expressed as mg gallic acid equivalents (GAE) per gram of dry weight (DW) of walnut shell (mg GAE/g DW) using the following equation:

$$
A=10.179 * C+0.0592\left(R^{2}=0.999\right)
$$

where $A$ is the absorbance and $C$ is the concentration (mg GAE/g DW).

\subsection{Scanning Electron Microscopy (SEM)}

A Quanta 3D FEG SEM (FEI, USA) from the Purdue Life Science Microscopy Facility was used to image the walnut shell and powder before and after treatment. The instrument was operated at $10.0 \mathrm{kV}$. Samples were sputter-coated with a thin layer of gold-palladium for $60 \mathrm{~s}$ at room temperature before imaging.

\subsection{Statistical Analysis}

Analysis of the variance (ANOVA) was conducted using SPSS, Version 23.0 statistical software (SPSS Inc., Chicago, IL, USA). All experimental results were re- 
ported as means of triplicate measurements.

\section{Results and Discussion}

\subsection{Surface Structure of the Walnut Shell}

A hard and thick woody shell that protects the oil-rich content of the nut surrounds the walnut kernel. Shells like these are fibrous with a high lignin content, low water absorption and a high resistance to natural degradation [27]. Lignin is a complex polyphenolic amorphous polymer with a three-dimensional network. The secondary wall of the shell comprises of cellulose and densely cross-linked lignin that provides mechanical support and enhances the hardness of the well call [28]. The lignin content of walnut shells $(52.3 \%)$ is much higher than other materials such as hard beech wood (22.2\%) and soft spruce wood (29\%) [3]. Furthermore, the lignin content is also correlated to the mechanical strength and thickness of the walnut shell [29]. Due to this particular quality, it is very important to crack and loosen the dense structure in order for the solvent to penetrate the cell to extract the phenolic compounds. Thus, to produce a higher yield of phenolic compounds, a proper extraction method and size of solute is critical.

\subsection{Comparison of the Total Phenolic Content from Different Extraction Methods}

In this study, three different methods were used: shaking, ultrasonic bath and ultrasonic probe. The three extraction methods were conducted at room temperature with $50 \%$ ethanol for 15 min with a 20 solvent to solid ratio. Figure 1 shows that the average total phenolic content for shaking, ultrasonic bath and ultrasonic probe was $20.6 \mathrm{mg} \mathrm{GAE} / \mathrm{g} \mathrm{DW}, 25.8 \mathrm{mg} \mathrm{GAE} / \mathrm{g} \mathrm{DW}$ and $51.2 \mathrm{mg}$ GAE/g DW, respectively. UAE with the bath and probe provided a higher total phenolic content than the shaking method. In other words, using UAE increased the efficiency of phenolic extraction by $20 \%$ with an ultrasonic bath and by an even greater $250 \%$ with an ultrasonic probe submerged in the liquid containing walnut shell particles.

Using high power ultrasound induces various effects on the physical, mechanical, chemical and biochemical properties of food and biomass materials [23]. UAE creates vigorous physical forces that allow for greater penetration of the solvent into the cell matrix, thereby increasing the solid to liquid contact [21] and enhancing the extraction of phenolic compounds from the walnut shells. Still, there is a significant difference between the ultrasonic bath method and ultrasonic probe method. In an ultrasonic bath, cavitation occurs irregularly and uncontrollably throughout the tank. In comparison, an ultrasonic probe provides a highly localized intensity that results in a higher efficiency of the sonication process [30]. It has been demonstrated that, under conditions similar to our experimental parameters, high cavitation pressures of the order of GPa are created only by suitable combinations of the drive frequency, the amplitude of the pressure field and the initial bubble size-conditions that occur only in a 
narrow zone below the probe [31]. Otherwise, predicted pressures around cavitation bubbles are of the order MPa and even up to $0.1 \mathrm{GPa}$ depending on the parameters of the pressure field. For this reason, cavitation pressures in the ultrasonic bath are expected to be at least one order of magnitude lower than pressures created by the ultrasonic probe. The ultrasonic probe produced the highest extraction yield, as seen in Figure 1, because the high cavitation pressures provided better disruptions of the dense shell structure. Direct reaction with the solvent system was further enhanced with strong acoustic streaming which brought walnut shell particles to the regions where the pressure was the highest and the cavitation was most vigorous.

\subsection{Effect of Particle Size on the Total Phenolic Content}

Altering the particle size of the solute changes the available surface area for reactions to occur, and thus should affect the extraction efficiency of phenolic compounds. Walnut shell particles of four size ranges were tested: the original shell size directly from the package ( $3-15 \mathrm{~mm}),>45$ mesh $(>0.354 \mathrm{~mm}), 45-100$ mesh $(0.354-0.150 \mathrm{~mm})$ and $<100 \mathrm{mesh}(<0.150 \mathrm{~mm})$. As shown in Figure 2, the total extracted phenolic content of the selected size of particle was $4.8 \mathrm{mg} \mathrm{GAE} / \mathrm{g} \mathrm{DW}$, $7.6 \mathrm{mg} \mathrm{GAE} / \mathrm{g}$ DW, $60.6 \mathrm{mg}$ GAE/g DW, $50.6 \mathrm{mg} \mathrm{GAE} / \mathrm{g} \mathrm{DW}$, respectively, indicating a general increasing trend of total phenolic content as particle size decreases. These results were in accordance with several other works conducted by researchers using different plant materials of varying particle sizes [9] [32] [33]. Smaller particles have a larger surface area to volume ratio and therefore reduce the mass transfer distance from solvent to cell matrix to induce maximum phenolic extraction as more of the cells are exposed to the ultrasonic waves [9] [34] [35] [36] [37].

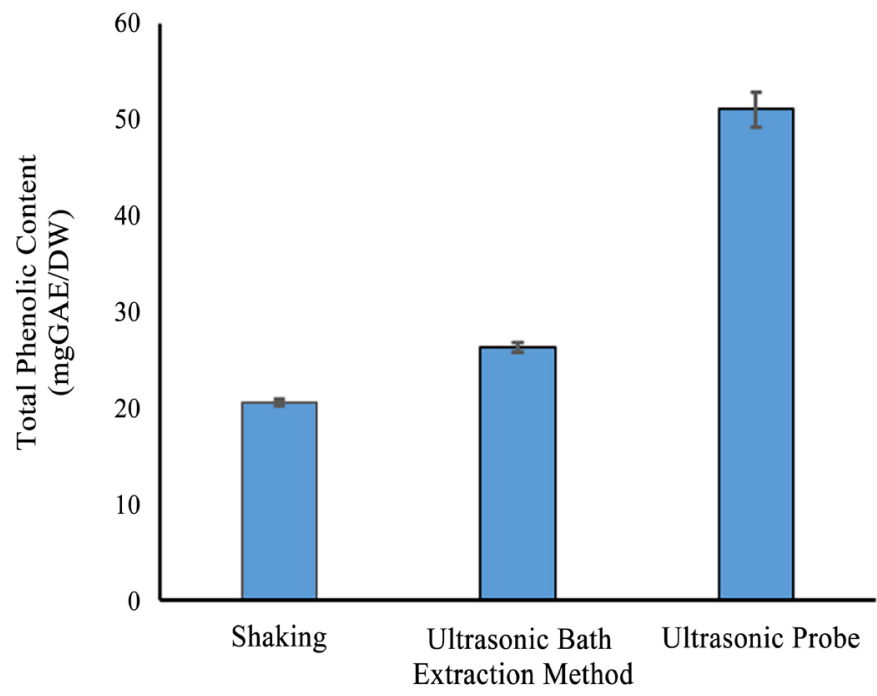

Figure 1. Effect of different extraction methods on the total phenolic content. The particle size, solvent to solid ratio, temperature, and treatment time were set at $<45 \mathrm{mesh}, 20,25^{\circ} \mathrm{C}$, and $15 \mathrm{~min}$, respectively. 


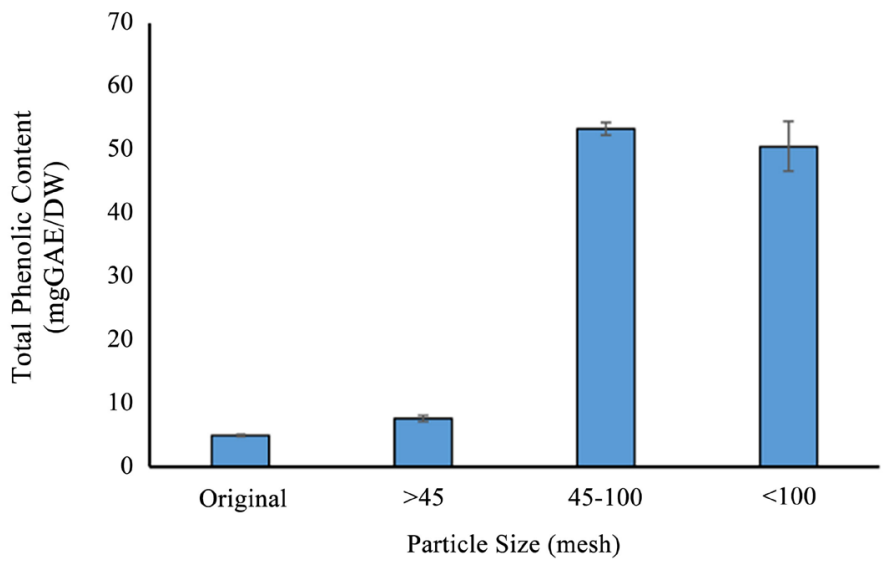

Figure 2. Effect of various particle sizes of walnut shell powder on total phenolic content. The ultrasonic probe method was performed at $25^{\circ} \mathrm{C}$ for $15 \mathrm{~min}$ with a solvent to solid ratio of 20 .

However, our results demonstrate that the phenolic content decreased slightly when the particle size was $<100$ mesh. The most probable explanation is the existence of bubbles that nucleate on the walnut particles dispersed in the solvent. The critical bubble radius is [38]

$$
r_{c}=\frac{2 \sigma}{p_{G}-p_{L}}
$$

where $\sigma$ is the liquid-gas surface tension, $p_{G}$ is the gas pressure inside the bubble and $p_{L}$ is the pressure in the liquid phase. This implies that gas bubbles cannot nucleate on particles that are below a certain size. Also, cavities that exist on solid particles are favorable nucleation sites for bubbles [39]. Walnut particles are fragmented more efficiently by cavitation bubbles that are attached to them than by short range shock waves emitted from free collapsing bubbles. For these two reasons, less fragmentation should be expected from particles that are smaller than a certain critical size.

\subsection{SEM Analysis of the Surface Characteristics of the Walnut Shell after Mechanical Force and UAE Treatment}

The structure of the fractured surface of the shell walls can be seen from SEM imaging as shown in Figure 3(A). The cross section of the walnut shell can be divided into two regions. The outside region is about 2.5 - 3 times thicker than the inside region. The outer cells are dense and more resistant to impact due to the harder structure and thus resist deformation and protect the nut from attacking insects, diseases, etc.

Mechanical forces during grinding reduced the particle sizes of the walnut shells and increased the available surface area. The SEM image in Figure 3(B) displays that the outer and inner regions of the shell still exist after grinding, and the fractured surface did not change much when the particle size was larger than 45 mesh $(>0.354 \mathrm{~mm})$. However, when the particle size was between $45-100$ mesh $(0.354-0.150 \mathrm{~mm})$, the outer and inner regions of the shell broke into small 
pieces, as presented in Figure 3(C), that significantly increased the surface area. Moreover, in Figure 3(D), many more porous particles appeared as the structure was ground more and screened through 100 mesh $(<0.150 \mathrm{~mm})$. More phenolic compounds are stored in dense structures containing high lignin and cellulose, giving a positive correlation between phenolic content and the amount of lignin and cellulose [29].

As illustrated in Figure 4(A), the untreated walnut shell powder had tight and close cells, and the cross-section surface had pits and embossments that correspond to cell walls and cell lumens, respectively. In Figure 4(B), the walnut shell that was shaken shows a slight change in morphology. Unlike the shaking method, the walnut shell extracted by an ultrasonic bath formed pits by exfoliated cell as seen in Figure 4(C). Figure 4(D) of the ultrasonic probe treated shell indicates that the cell walls collapsed, and the general structure puffed with many open holes. During the treatment, high cavitation pressures caused surface erosion and fragmentation [19]. Therefore, the solvent could more easily penetrate into the cell to enhance the extraction efficiency and increase the antioxidant activity of the walnut shell extract [25] [40] [41]. Furthermore, vibrations inevitably nucleated bubbles inside newly created pores. The oscillations and collapses of these bubbles created an internal pressure that led to an expansion of the structure and further erosion and propagation of cracks and cavities.
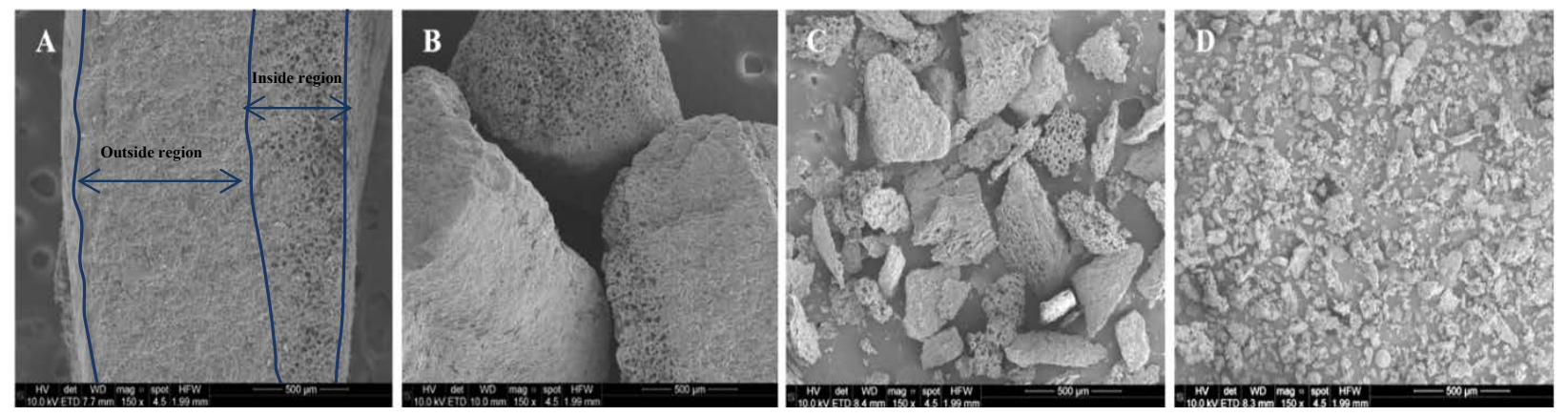

Figure 3. SEM images of the various particle sizes of the ground walnut shell. (A) Original; (B) >45 mesh; (C) 45 - 100 mesh; (D) $<100$ mesh.
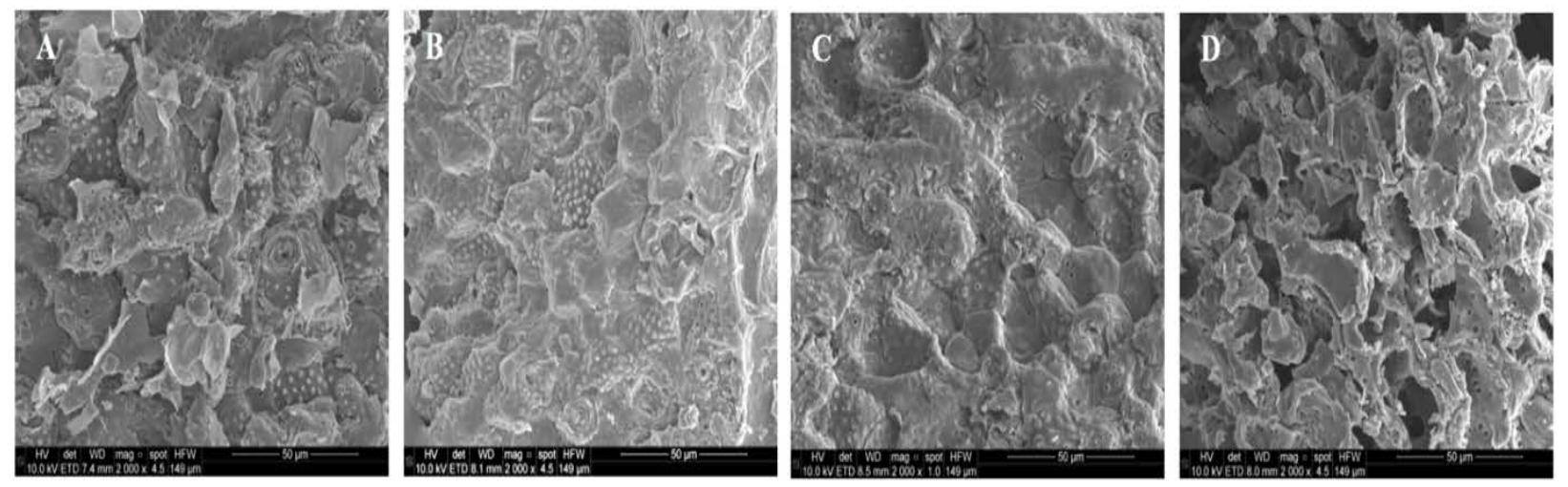

Figure 4. SEM images of the walnut shell after each treatment. (A) Untreated; (B) Shaking; (C) Ultrasonic Bath; (D) Ultrasonic Probe. 


\section{Conclusion}

The high lignin content of walnut shells allows for a special hard and dense structure in the cell wall. This study demonstrated that the best method to extract phenolic compounds from a walnut shell is UAE with a probe. This technique creates agitation with a probe immersed into the sample that directly disrupts cell structure and speeds up solvent transferring into the cell, thereby releasing more phenolic compounds from the cell matrix. In addition, the mechanical forces from grinding and the waves from ultrasonic vibration reduce the particle size of the shells and enlarge the available surface area for better extraction yields of phenolic compounds. The SEM imaging on the cross section of the walnut shell shows that there is an inside and outside layer to the cell structure. The outside layer is around 2.5 - 3 times thicker than the inside one. The inner cells are loose and porous, making them easy to penetrate after cracking the outside layer. SEM observations also show that the ultrasonic probe treated cells had many ruptures and open holes with a loose and puffy structure. Based on the results above, future work should be conducted to optimize the parameters of UAE with an ultrasonic probe such as altering the treatment time, amplitude of the drive pressure, temperature, etc. Furthermore, the phenolic compounds profile by HPLC and the antioxidant activity properties (e.g. DPPH, ABTs) of phenolic compounds should be determined.

\section{Acknowledgements}

We thank Sierra Orchards for providing the walnut shells for this project. The authors also would like to thank Xingtao Liu for the help with the SEM imaging and $\mathrm{Dr}$. Wilson $\mathrm{Xu}$ for the supervision and maintenance of the ultrasound equipment. Financial support is from the John \& Emma Tse through the Li-Fu Chen Memorial Laboratory fund and the Center for Materials Processing Research (CMPR).

\section{Conflicts of Interest}

The authors declare no conflicts of interest regarding the publication of this paper.

\section{References}

[1] Oliveira, I., Sousa, A., Ferreira, I.C.F.R., Bento, A. and Pereira, J.A. (2008) Total Phenols, Antioxidant Potential and Antimicrobial Activity of Walnut (Juglans regia L.) Green Husks. Food and Chemical Toxicology, 46, 2326-2331. https://doi.org/10.1016/j.fct.2008.03.017

[2] Ayrilmis, N., Kaymakci, A. and Ozdemir, F. (2013) Physical, Mechanical, and Thermal Properties of Polypropylene Composites Filled with Walnut Shell Flour. Journal of Industrial and Engineering Chemistry, 19, 908-914. https://doi.org/10.1016/j.jiec.2012.11.006

[3] Dermibaş, A. (2005) Estimating of Structural Composition of Wood and Non-Wood Biomass Samples. Energy Sources, 27, 761-767. 
https://doi.org/10.1080/00908310490450971

[4] Kulkarni, M.C. and Ochoa, O.O. (2012) Light Weight Composite Proppants: Computational and Experimental Study. Mechanics of Advanced Materials and Structures, 19, 109-118. https://doi.org/10.1080/15376494.2011.572241

[5] Schüler, P., Speck, T., Bührig-Polaczek, A. and Fleck, C. (2014) Structure-Function Relationships in Macadamia integrifolia Seed Coats-Fundamentals of the Hierarchical Microstructure. PLOS ONE, 9, e102913.

[6] Almonte-Flores, D.C., Paniagua-Castro, N., Escalona-Cardoso, G. and Rosales-Castro, M. (2015) Pharmacological and Genotoxic Properties of Polyphenolic Extracts of Cedrela odorata L. and Juglans regia L. Barks in Rodents. Evidence-Based Complementary and Alternative Medicine, 2015, Article ID: 187346.

[7] Singh, A., Kuila, A., Yadav, G. and Banerjee, R. (2011) Process Optimization for the Extraction of Polyphenols from Okara. Food Technology and Biotechnology, 49, 322-328.

[8] Balasundram, N., Sundram, K. and Samman, S. (2006) Phenolic Compounds in Plants and Agri-Industrial By-Products: Antioxidant Activity, Occurrence, and Potential Uses. Food Chemistry, 99, 191-203.

https://doi.org/10.1016/j.foodchem.2005.07.042

[9] Samavardhana, K., Supawititpattana, P., Jittrepotch, N., Rojsuntornkitti, K. and Kongbangkerd, T. (2015) Effects of Extracting Conditions on Phenolic Compounds and Antioxidant Activity from Different Grape Processing Byproducts. International Food Research Journal, 22, 1169-1179. http://www.ifrj.upm.edu.my/22\%20(03)\%202015/(41).pdf

[10] Jalili, A., Heydari, R., Sadeghzade, A. and Alipour, S. (2012) Reducing Power and Radical Scavenging Activities of Phenolic Extracts from Juglans regia Hulls and Shells. African Journal of Biotechnology, 11, 9040-9047.

[11] Xu, P., Bao, J., Gao, J., Zhou, T. and Wang, Y. (2012) Optimization of Extraction of Phenolic Antioxidants from Tea (Camellia sinensis L.) Fruit Peel Biomass Using Response Surface Methodology. BioResources, 7, 2431-2442.

https://bioresources.cnr.ncsu.edu/BioRes_07/BioRes_07_2_2431_Xu_BGZW_Opt Extrac_Phenolic_Tea_Peel_RSM_2767.pdf https://doi.org/10.15376/biores.7.2.2431-2443

[12] Ameer, K., Shahbaz, H.M. and Kwon, J.H. (2017) Green Extraction Methods for Polyphenols from Plant Matrices and Their Byproducts: A Review. Comprehensive Reviews in Food Science and Food Safety, 16, 295-315. https://doi.org/10.1111/1541-4337.12253

[13] Takeuchi, T.M., Rubano, M.L. and Meireles, M.A.A. (2010) Characterization and Functional Properties of Macela (Achyrocline satureioides) Extracts Obtained by Supercritical Fluid Extraction Using Mixtures of $\mathrm{CO}_{2}$ plus Ethanol. Food and Bioprocess Technology, 3, 804-812. https://doi.org/10.1007/s11947-009-0309-5

[14] Ghafoor, K., Park, J. and Choi, Y.H. (2010) Optimization of Supercritical Fluid Extraction of Bioactive Compounds from Grape (Vitis labrusca B.) Peel by Using Response Surface Methodology. Innovative Food Science \& Emerging Technologies, 11, 485-490. https://doi.org/10.1016/j.ifset.2010.01.013

[15] Hossain, M.B., Brunton, N.P., Patras, A., Tiwari, B., O’Donnell, C.P., Martin-Diana, A.B. and Barry-Ryan, C. (2012) Optimization of Ultrasound Assisted Extraction of Antioxidant Compounds from Marjoram (Origanum majorana L.) Using Response Surface Methodology. Ultrasonics Sonochemistry, 19, 582-590. https://doi.org/10.1016/j.ultsonch.2011.11.001 
[16] Pereira, R.N., Rodrigues, R.M., Genisheva, Z., Oliveira, H., de Freitas, V., Teixeira, J.A. and Vicente, A.A. (2016) Effects of Ohmic Heating on Extraction of Food-Grade Phytochemicals from Colored Potato. LWT-Food Science and Technology, 74, 493-503. https://doi.org/10.1016/j.lwt.2016.07.074

[17] Chemat, F., Zill-E-Huma and Khan, M.K. (2011) Applications of Ultrasound in Food Technology: Processing, Preservation and Extraction. Ultrasonics Sonochemistry, 18, 813-835. https://doi.org/10.1016/j.ultsonch.2010.11.023

[18] Capelo-Martínez, J.L. (2009) Ultrasound in Chemistry: Analytical Applications. Wiley-VCH, Weinheim.

[19] Chemat, F., Rombaut, N., Sicaire, A.G., Meullemiestre, A., Fabiano-Tixier, A.S. and Abert-Vian, M. (2017) Ultrasound Assisted Extraction of Food and Natural Products. Mechanisms, Techniques, Combinations, Protocols and Applications. A Review. Ultrasonics Sonochemistry, 34, 540-560.

https://doi.org/10.1016/j.ultsonch.2016.06.035

[20] Feng, S., Luo, Z., Tao, B. and Chen, C. (2015) Ultrasonic-Assisted Extraction and Purification of Phenolic Compounds from Sugarcane (Saccharum officinarum L.) Rinds. LWT-Food Science and Technology, 60, 970-976. https://doi.org/10.1016/j.lwt.2014.09.066

[21] Rodrigues, S. and Fernandes, F.A.N. (2009) Ultrasound-Assisted Extraction. Stewart Postharvest Review, 5, 1-11. https://doi.org/10.2212/spr.2009.5.1

[22] Mason, T.J., Chemat, F. and Vinatoru, M. (2011) The Extraction of Natural Products Using Ultrasound or Microwaves. Current Organic Chemistry, 15, 237-247. https://doi.org/10.2174/138527211793979871

[23] Awad, T.S.S., Moharram, H.A.A., Shaltout, O.E.E., Asker, D. and Youssef, M.M.M. (2012) Applications of Ultrasound in Analysis, Processing and Quality Control of Food: A Review. Food Research International, 48, 410-427.

https://doi.org/10.1016/j.foodres.2012.05.004

[24] Žlabur, J.Š., Voća, S., Dobričević, N., Brnčić, M., Dujmić, F. and Brnčić, S.R. (2015) Optimization of Ultrasound Assisted Extraction of Functional Ingredients from Stevia rebaudiana Bertoni Leaves. International Agrophysics, 29, 231-237. https://doi.org/10.1515/intag-2015-0017

[25] Patist, A. and Bates, D. (2008) Ultrasonic Innovations in the Food Industry: From the Laboratory to Commercial Production. Innovative Food Science \& Emerging Technologies, 9, 147-154. https://doi.org/10.1016/j.ifset.2007.07.004

[26] Jalili, A. and Sadeghzade, A. (2012) Comparative Phenolic Profile of Persian Walnut (Juglans regia L.) Leaves Cultivars Grown in Iran Amir. African Journal of Biochemistry Research, 6, 33-38.

[27] Srinivasan, A. and Viraraghavan, T. (2009) Removal of Oil by Walnut Shell Media. Bioresource Technology, 99, 8217-8220.

https://doi.org/10.1016/j.biortech.2008.03.072

[28] Chen, H. (2014) Biotechnology of Lignocellulose: Theory and Practice. Chemical Industry Press, Beijing and Springer, Dodrechet.

[29] Zhao, S., Wen, J., Wang, H., Zhang, Z. and Li, X. (2016) Changes in Lignin Content and Activity of Related Enzymes in the Endocarp during the Walnut Shell Development Period. Horticultural Plant Journal, 3, 141-146.

[30] Dhanalakshmi, N.P. and Nagarajan, R. (2011) Ultrasonic Intensification of the Chemical Degradation of Methyl Violet: An Experimental Study. International Journal of Chemical and Molecular Engineering, 5, 1019-1024. 
http://scholar.waset.org/1307-6892/13939

[31] Rakita, M. and Han, Q. (2017) Influence of Pressure Field in Melts on the Primary Nucleation in Solidification Processing. Metallurgical and Materials Transactions B: Process Metallurgy and Materials Processing Science, 48, 2232-2244. https://doi.org/10.1007/s11663-017-1029-2

[32] Landbo, A.K. and Meyer, A.S. (2001) Enzyme-Assisted Extraction of Antioxidative Phenols from Black Currant Juice Press Sesidues (Ribes nigrum). Journal of Agricultural and Food Chemistry, 49, 3169-3177. https://doi.org/10.1021/jf001443p

[33] Rajha, H.N., Darra, N.E., Hobaika, Z., Boussetta, N., Vorobiev, E., Maroun, R.G. and Louka, N. (2014) Extraction of Total Phenolic Compounds, Flavonoids, Anthocyanins and Tannins from Grape Byproducts by Response Surface Methodology. Influence of Solid-Liquid Ratio, Particle Size, Time, Temperature and Solvent Mixtures on the Optimization Process. Food and Nutrition Sciences, 5, 397-409. https://doi.org/10.4236/fns.2014.54048

[34] Baldosano, H.Y., Beatriz, M., Castillo, M.G., Elloran, C.D.H. and Bacani, F.T. (2015) Effect of Particle Size, Solvent and Extraction Time on Tannin Extract from Spondias purpurea Bark through Soxhlet Extraction. DLSU Research Congress, 3, 4-9. http://www.dlsu.edu.ph/conferences/dlsu_research_congress/2015/proceedings/FN H/008FNH_Bacani_FT.pdf

[35] Qu, W., Pan, Z. and Ma, H. (2010) Extraction Modeling and Activities of Antioxidants from Pomegranate Marc. Journal of Food Engineering, 99, 16-23. https://doi.org/10.1016/j.jfoodeng.2010.01.020

[36] Durling, N.E., Catchpole, O.J., Grey, J.B., Webby, R.F., Mitchell, K.A., Foo, L.Y. and Perry, N.B. (2007) Extraction of Phenolics and Essential Oil from Dried Sage (Salvia officinalis) Using Ethanol-Water Mixtures. Food Chemistry, 101, 1417-1424. https://doi.org/10.1016/j.foodchem.2006.03.050

[37] Vinatoru, M. (2001) An Overview of the Ultrasonically Assisted Extraction of Bioactive Principles from Herbs. Ultrasonics Sonochemistry, 8, 303-313. https://doi.org/10.1016/S1350-4177(01)00071-2

[38] Blander, M. and Katz, J.L. (1975) Bubble Nucleation in Liquids. AIChE Journal, 21, 833-848. https://doi.org/10.1002/aic.690210502

[39] Wilt, P.M. (1986) Nucleation Rates and Bubble Stability in Water-Carbon Dioxide Solutions. Journal of Colloid and Interface Science, 112, 530-538. https://doi.org/10.1016/0021-9797(86)90122-0

[40] Ashokkumar, M., Sunartio, D., Kentish, S., Mawson, R., Simons, L., Vilkhu, K. and Versteeg, C. (2008) Modification of Food Ingredients by Ultrasound to Improve Functionality: A Preliminary Study on a Model System. Innovative Food Science \& Emerging Technologies, 9, 155-160. https://doi.org/10.1016/j.ifset.2007.05.005

[41] Kataoka, H. (2003) New Trends in Sample Preparation for Clinical and Pharmaceutical Analysis. TrAC Trends in Analytical Chemistry, 22, 232-244. https://doi.org/10.1016/S0165-9936(03)00402-3 